\title{
INFLUENCE OF EMERGENCY LAY-BYS ON SMOKE STRATIFICATION IN CASE OF FIRE IN BI-DIRECTIONAL TUNNEL: PARALLEL SIMULATION
}

\author{
Weisenpacher, P. ${ }^{(a)}$, Valasek, L. ${ }^{(b)}$, Glasa, J. ${ }^{(c)}$

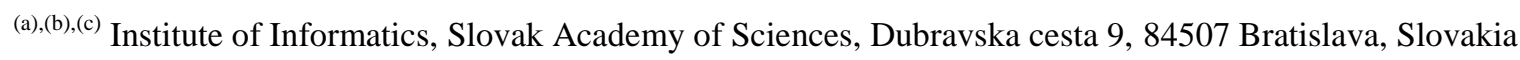 \\ ${ }^{(a)}$ upsyweis@ @avba.sk, ${ }^{(b)}$ Lukas.Valasek@ savba.sk, ${ }^{(c)}$ Jan.Glasa@ savba.sk
}

\begin{abstract}
The main goal of longitudinal ventilation in case of fire in bi-directional road tunnel is to maintain smoke stratification, which is necessary for safe evacuation of people. This study investigates the influence of emergency lay-bys on smoke stratification in a $900 \mathrm{~m}$ long road tunnel by computer simulation using a parallel version of Fire Dynamics Simulator. The calculations were performed on the high performance computer cluster at the Institute of Informatics, Slovak Academy of Sciences in Bratislava (Slovakia). Several scenarios of fire in the tunnel without and with two laybys were simulated and compared. The most significant differences between smoke visibilities in both cases can be observed in the area of the lay-by located downstream of the fire. Several other differences are analysed as well.
\end{abstract}

Keywords: tunnel ventilation system, longitudinal ventilation, Fire Dynamics Simulator, parallel simulation, high-performance computing

\section{INTRODUCTION}

The concept of smoke stratification is used in fire safety measures in various types of structures with high compartments, for example in atriums and large corridors (Klote and Milke 1992). If upward movement of smoke ceases and the smoke layer does not descend below the level of human head, tenable conditions for human life are maintained and safe evacuation in case of fire is possible. Large dimensions of road tunnels enable to use the concept of smoke stratification for fire ventilation strategy in case of bi-directional tunnels equipped with longitudinal ventilation (Boehm 2008). It is assumed that in case of traffic accident and subsequent car fire, vehicles and people are trapped on both sides of fire. Proper airflow velocity in the tunnel induced by jet fans could maintain the stratification of smoke layer for several minutes to ensure the safe evacuation of people on both sides of fire. If smoke stratification was not maintained, tenable conditions for human life downstream of the fire would disappear. Capability of maintaining smoke stratification is strongly influenced by tunnel geometry. From the point of view of tunnel geometry complexity, one of the most important features of the tunnel are niches for emergency lay-bys.

Lay-bys in tunnels allow vehicles to stop inside tunnel without blocking the carriageway. This reduces traffic disruption and the risk of collision. It is easier and safer for passengers to get out of their vehicle in a lay-by. Lay-by niches are equipped by various operating and safety installations. They are provided typically every $1000 \mathrm{~m}$ in the tunnel (Rattei 2010).

In this study we investigate the influence of lay-bys on smoke stratification in a $900 \mathrm{~m}$ long road tunnel using the well-known CFD code Fire Dynamics Simulator (FDS), version 6. Visibility at human head level is considered to be a measure of smoke stratification. In this way, a tunnel without lay-bys and a more realistic tunnel with two lay-bys are considered. Smoke movements in both cases are studied and compared for several selected fire scenarios and the influence of laybys on smoke stratification and visibility at head level is evaluated.

\section{FDS TUNNEL MODEL}

\subsection{Fire Dynamics Simulator}

FDS is a CFD-based simulation system for modelling fire and fire-driven fluid flows developed by the National Institute of Standards and Technology (NIST), USA in cooperation with the VTT Technical Research Centre of Finland (McGrattan, Hostikka, McDermott, Floyd, Weinschenk, and Overholt 2017). FDS numerically solves a form of conservation equations for low-speed thermally-driven flows with an emphasis on the smoke and heat transport from fire.

The core algorithm is a very efficient explicit predictorcorrector scheme, second order accurate in space and time. FDS also includes models of fire related processes such as turbulence, thermal radiation, pyrolysis, combustion of the pyrolysis products, conductive heat transfer, etc.

Input data for simulation include the rectangular geometry of the scenario (size and shape of compartments, locations and dimensions of all relevant objects), material properties of object surfaces (ignition temperature, thermal conductivity, specific heat, density, emissivity, heat of evaporation, etc.) and the fire HRR. 
FDS supports several models of parallelization of calculation (Weisenpacher, Glasa, and Sipkova 2016). The Message Passing Interface (MPI) model was chosen for this study due to its efficiency enabling to deal with significant computational requirements of fire simulation in large tunnel.

The execution of simulation on the HPC (high performance computing) cluster is realized by the invocation of the corresponding FDS manager script accompanied with the input parameters.

The simulations were carried out on the SIVVP HPC cluster at the Institute of Informatics, Slovak Academy of Sciences, Bratislava (Slovakia) (SIVVP). It is an IBM dx360 M3 cluster consisting of 54 computational nodes (23 Intel E5645 @ 2.4 GHz CPU, 48 GB RAM); the total number of cores is 648. The nodes are connected by the Infiniband interconnection network with the bandwidth of $40 \mathrm{Gbit} / \mathrm{s}$ per link and direction.

\subsection{Tunnel Model Description}

The scheme of the tunnel with two lay-bys is shown in Fig. 1. The $900 \mathrm{~m}$ long tunnel has a horseshoe cross section of dimensions $10.8 \mathrm{~m}$ (width) and $6.8 \mathrm{~m}$ (height). The lay-bys are located at $373 \mathrm{~m}$ and $635.6 \mathrm{~m}$ from the west tunnel portal. The first lay-by is located on the left side of the tunnel, the second one on the right side. The niches are $50 \mathrm{~m}$ long and $2.2 \mathrm{~m}$ wide with the maximal height of vaulted ceiling of $7.8 \mathrm{~m}$.

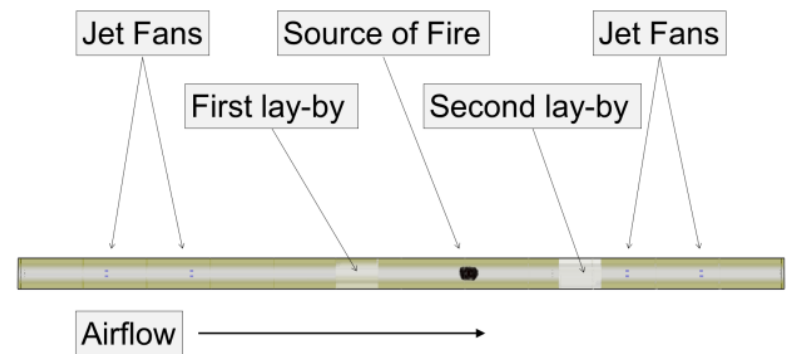

Figure 1: Scheme of the Tunnel with Two Lay-Bys

The tunnel is equipped with four pairs of jet fans located at $101 \mathrm{~m}, 201 \mathrm{~m}, 716 \mathrm{~m}$ and $801 \mathrm{~m}$. They are modelled using the HVAC feature included in FDS. Two rectangular vents of dimensions $0.6 \mathrm{~m} \times 0.8 \mathrm{~m}$ with a prescribed normal velocity are used to model the inlet and outlet of a jet fan. The length of the jet fan shroud is $3.8 \mathrm{~m}$. The maximal volume flow is $18.62 \mathrm{~m}^{3} \cdot \mathrm{s}^{-1}$.

The tunnel dimensions as well as the parameters of the jet fans are typical for some tunnels which are currently under construction in Slovakia (Danisovic, Sramek, Hodon, and Hudik 2017).

Fire is located at $530 \mathrm{~m}$, i.e. between the lay-bys. Three different heat release rates (HRR) are considered: $3 \mathrm{MW}, 5 \mathrm{MW}$ and $12 \mathrm{MW}$ corresponding to a small passenger car fire, large passenger car fire and truck fire, respectively. The fire soot yield is 0.2 .

For each value of HRR four fire scenarios are simulated:
- horizontal tunnel without lay-bys (xMW-0)

- horizontal tunnel with two lay-bys (xMW-0L)

- $\quad$ tunnel with $2^{\circ}$ slope without lay-bys (xMW-2)

- tunnel with $2^{\circ}$ slope with two lay-bys (xMW2L),

where $\mathrm{x}=3,5,12$.

The tunnel cross section as well as the jet fans location and performance are the same in all scenarios.

The fire HRR increases linearly since the beginning of the simulation, reaching its maximal value after $40 \mathrm{~s}$ of the fire. Jet fans performance is modelled via the RAMP feature in FDS. Adaptive algorithm increases or decreases their performance in order to achieve the prescribed target velocity of $1.2 \mathrm{~m} . \mathrm{s}^{-1}$ required by Slovak regulation (TP 12/2011).

The computational domain size is $900 \mathrm{~m}$ x $18 \mathrm{~m} \mathrm{x} 8 \mathrm{~m}$ for all considered tunnels. For $20 \mathrm{~cm}$ mesh resolution, the domain consists of $4,500 \times 90 \times 40$ cells. The total number of cells is $16,200,000$. In order to deal with significant computational requirements and to increase the simulations performance, the parallel MPI version 6.5.2 of FDS was used. The computational domain was decomposed into 12 meshes, each of them assigned to one MPI process (one CPU core).

The total CPU time strongly depends on specifications of each fire scenario. It varies from 269 hours for $3 \mathrm{MW}-2$ scenario to 993 hours for $12 \mathrm{MW}-2$ scenario.

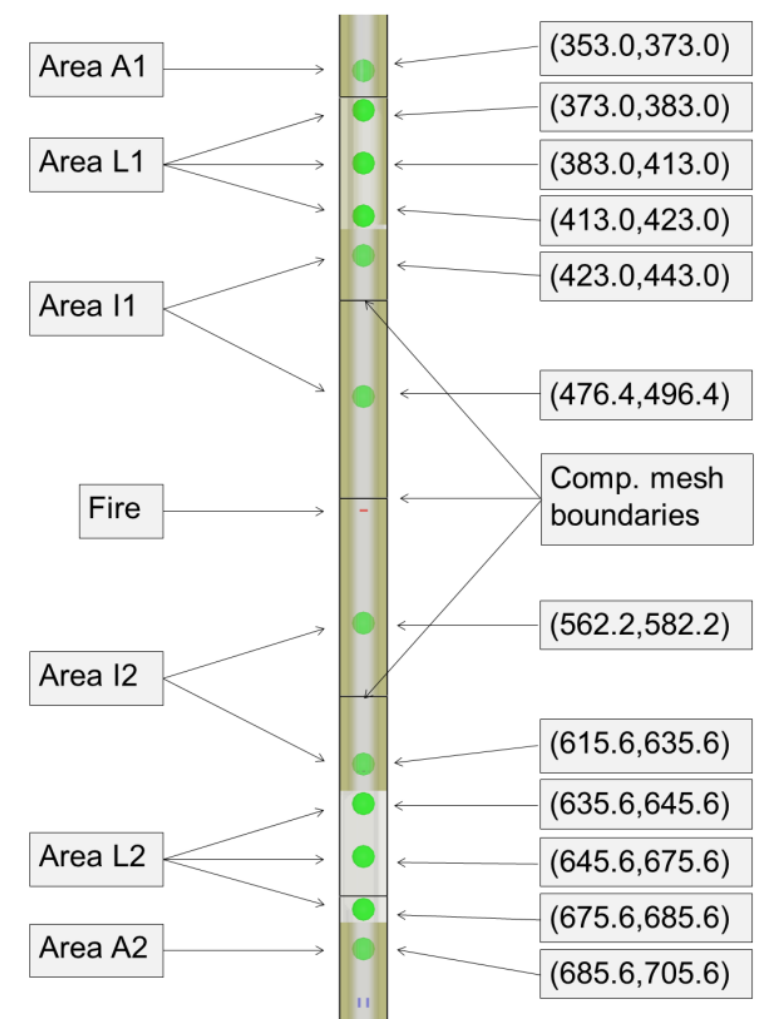

Figure 2: Six Areas of the Tunnel in Which Averaged Visibility Is Evaluated and 12 Sectors Used For Their Definition, Their Location and Dimensions 


\section{SIMULATION RESULTS}

Average visibility at human head level is studied in six areas of the tunnel depicted in Fig. 2: in both lay-bys (L1 and L2), in front of the first lay-by (A1), behind the second lay-by (A2), between the lay-bys upstream and downstream of the fire (I1 and I2, respectively). Because of FDS limitations, averaged quantities must be evaluated within one computational mesh only. Therefore, it is useful to define 12 sectors in which the average visibility is evaluated and to determine the corresponding average quantities for six tested areas via weighted averages of these 12 values according to the scheme in Fig. 2. Finally, we obtain six time-dependent values describing conditions in particular areas of the tunnel from the point of view of smoke distribution.

Main tendencies of smoke movement are similar for all tested scenarios (see Fig. 3). Significant backlayering upstream of the fire increases with increasing HRR and decreases in sloped tunnels. Movement of smoke downstream is accelerated for higher HRR. However, there are several differences that must be analysed.

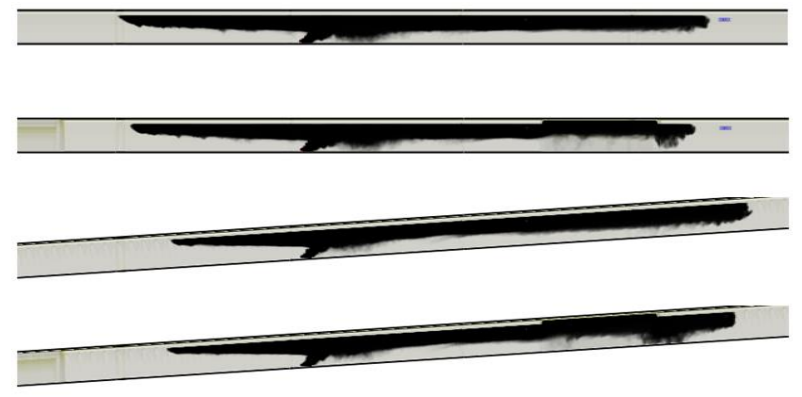

Figure 3: Smoke Movement for Four $5 \mathrm{MW}$ Fire Scenarios after $100 \mathrm{~s}$ to the Fire

\subsection{Passenger car fire scenarios}

Due to less significant backlayering caused by relatively low HRR there is no visibility drop in any of three areas upstream of the fire (A1, L1 and I1 areas) in passenger car fire scenarios.

Only slight drop of visibility occurs in front of the second lay-by (I2 area, downstream of the fire) for sloped tunnel scenario. However, in the case of horizontal tunnel the drop is considerable and after 200 $\mathrm{s}$ to the fire the conditions for human life become untenable (see Fig. 4). Note that the difference is caused by higher air velocity in front of the fire in the case of horizontal tunnel, which disrupts the stratification of the smoke layer downstream of the fire. Due to the higher buoyancy, such effect is attenuated in the sloped tunnel (Weisenpacher, Glasa, and Valasek 2017; Weisenpacher, Glasa, and Valasek 2018).

The similar patterns of visibility decrease can be observed also in the second lay-by (L2 area), although they are shifted in time due to its farther location in the tunnel (see Figs. 5 and 6). In these cases, the first significant differences between scenarios with and without lay-bys can be observed.

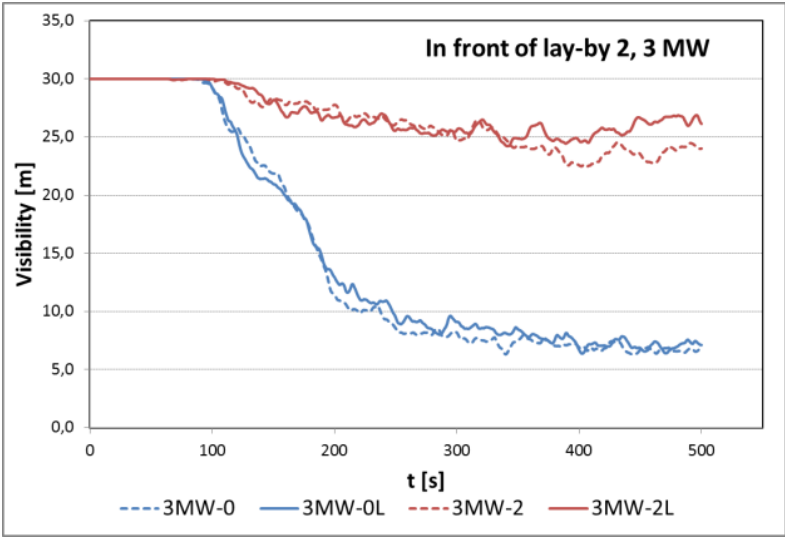

Figure 4: Average Visibility In Front of the Second Lay-By for 3 MW Fires

In the horizontal tunnel the lay-by geometry improves the conditions for people. Untenable conditions occur in all scenarios with horizontal tunnel; however, they occur later in scenarios with lay-bys. The effect is more pronounced for less intensive fire. For $3 \mathrm{MW}$ fire, untenable conditions occur later by more than 2 minutes in the 3MW-0L scenario (with lay-by) than in the $3 \mathrm{MW}-0$ scenario. In $5 \mathrm{MW}$ fire scenarios the corresponding difference is only $49 \mathrm{~s}$.

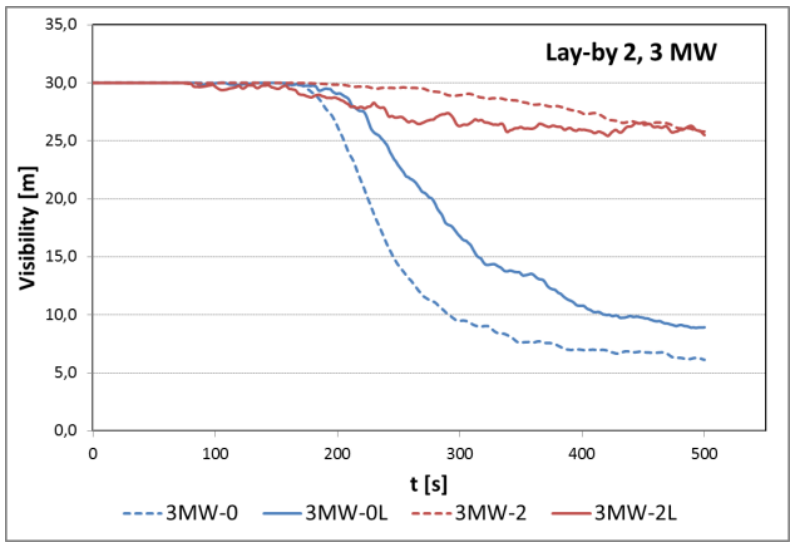

Figure 5: Average Visibility in the Second Lay-By for 3 MW Fires

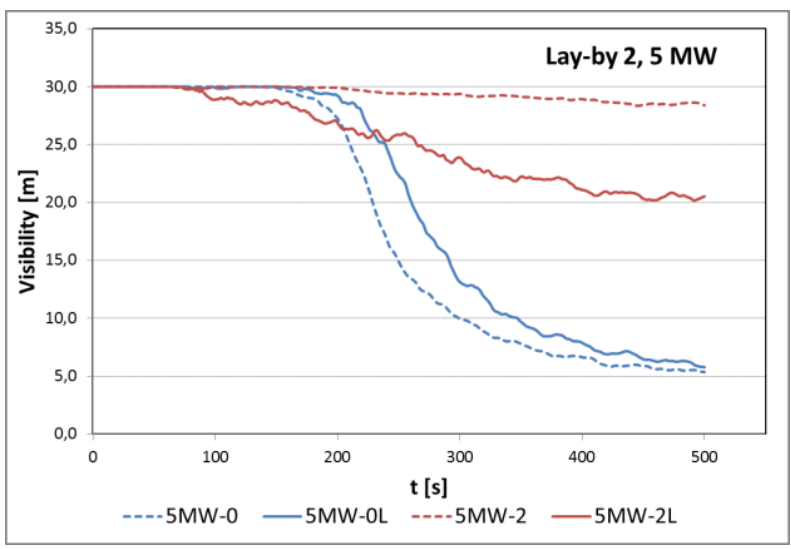

Figure 6: Average Visibility in the Second Lay-By for 5 MW Fires 
Note that in horizontal tunnel the visibility decrease starts behind the fire and the region with untenable conditions expands downstream. The higher ceiling in the lay-by enables the ascent of the smoke layer improving conditions at head level. The effect is more significant for thinner smoke layer in $3 \mathrm{MW}$ scenarios. In the sloped tunnel the visibility decrease is not critical and tenable conditions are maintained. The lay-by deteriorates visibility for both 3 and 5 MW scenarios; however, the effect is very slight in the cases of $3 \mathrm{MW}$ fires (see Fig. 5), while in the cases of 5MW fires the visibility decrease is more pronounced (see Fig. 6). Fig. 3 indicates a considerable visibility decrease occurring in the rear part of the lay-by due to the interaction of the smoke layer with the vertical wall delimiting the end of the lay-by. The smoke is pushed down causing extreme local decrease of the visibility at head level which also decreases the average visibility evaluated within the whole lay-by. The effect is obviously intensified by larger amount of smoke and its higher velocity which is why it is more significant in the case of $5 \mathrm{MW}$ fires. Smoke distribution patterns and their dependence on tunnel geometry and air flows are analysed in detail in the next section.

The vertical wall at the end of the lay-by causes significant drop of visibility in the A2 area (i.e. behind the lay-by) in all scenarios with lay-bys. After 5-6 minutes of the fire conditions in the $\mathrm{A} 2$ area are untenable in all scenarios with the exception of $3 \mathrm{MW}-2$ and 5MW-2, in which almost perfect visibility is maintained.

\subsection{Smoke distribution in the second lay-by}

Average visibility depicted in Figs. 5 and 6 does not capture local behaviour of smoke within lay-by. Vertical slices and horizontal slices at head level of visibility for four horizontal tunnel scenarios after $300 \mathrm{~s}$ are shown in Figs. 7 and 8. Yellow and red colour mark regions with untenable conditions, green colour marks tenable conditions and blue colour marks the regions with almost perfect visibility. Average visibility in the lay-by at that time is close to $10 \mathrm{~m}$ limit for all four considered simulations.

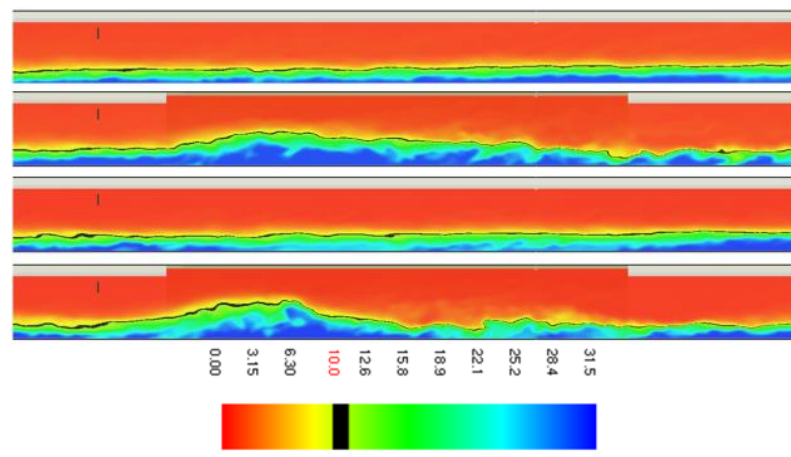

Figure 7: Vertical Slice of Visibility in the Second LayBy for Horizontal Tunnel Scenarios 3MW-0, 3MW-0L, $5 \mathrm{MW}-0$ and $5 \mathrm{MW}-0 \mathrm{~L}$ after $300 \mathrm{~s}$ to the Fire
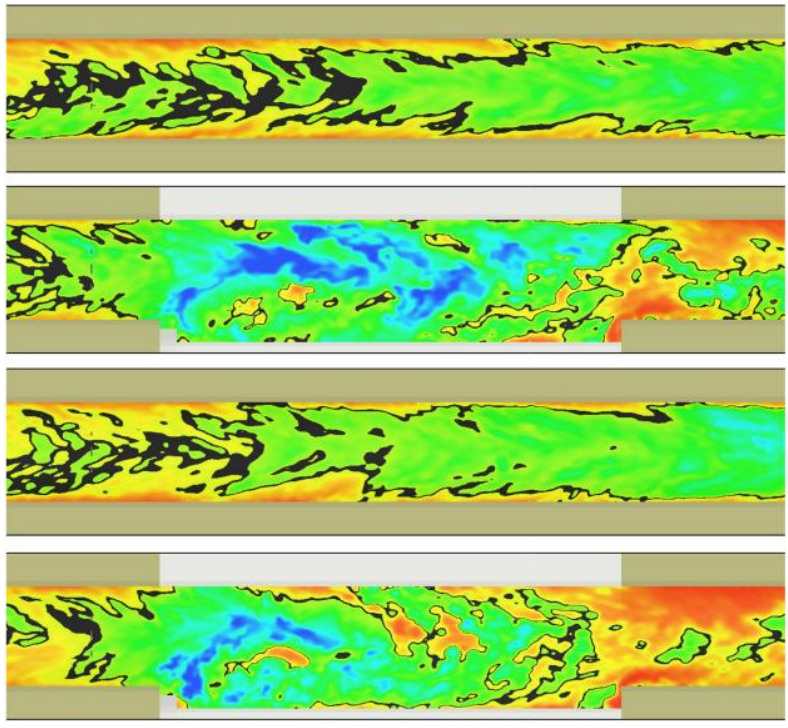

Figure 8: Horizontal Slice of Visibility at Head Level in the Second Lay-By for Horizontal Tunnel Scenarios $3 \mathrm{MW}-0,3 \mathrm{MW}-0 \mathrm{~L}, 5 \mathrm{MW}-0$ and $5 \mathrm{MW}-0 \mathrm{~L}$ after $300 \mathrm{~s}$ to the Fire

Higher ceiling of the lay-by improves the visibility at head level in the region of lay-by closer to fire, as the smoke ascends higher. The smoke layer becomes thinner. In Fig. 8 large regions with good visibility can be observed. On the other hand, interaction with the vertical wall at the end of the lay-by deteriorates visibility in the rear region of the lay-by, which is worse than in $\mathrm{xMW}-0$ scenarios.
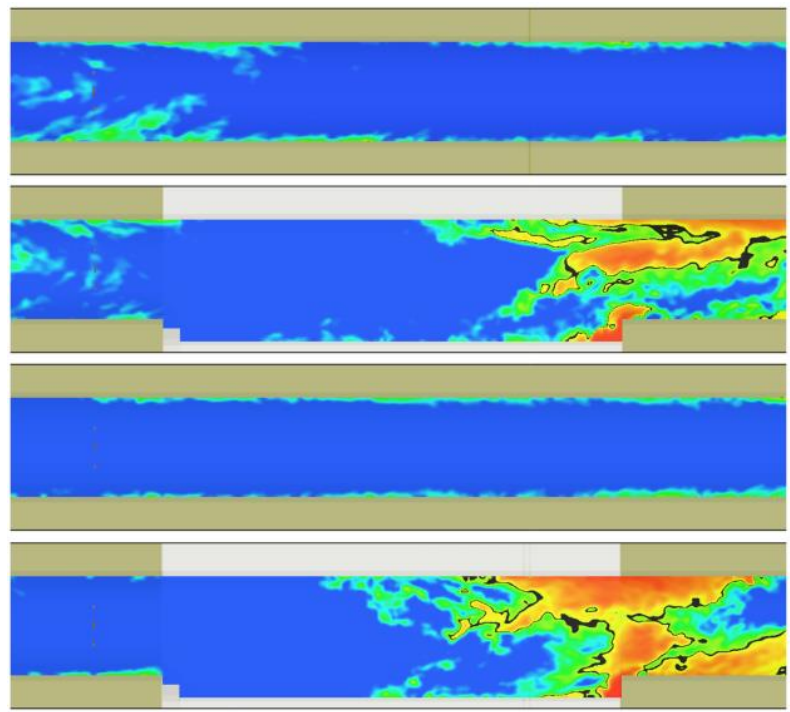

Figure 9: Horizontal Slice of Visibility at Head Level in the Second Lay-By for Sloped Tunnel Scenarios 3MW2, 3MW-2L, 5MW-2 and 5MW-2L after $300 \mathrm{~s}$ to the Fire

At $300 \mathrm{~s}$ to the fire conditions in the lay-by become untenable. The visibility drop starts near the tunnel walls and in the lay-by niche at the end of the lay-by. Regions with untenable conditions expand and merge so that they afflict the entire width of the lay-by. 
Similar pattern as in horizontal tunnel can be observed also in the case of sloped tunnel (see Fig. 9). The averaged visibility is significantly better than in horizontal tunnel in accordance with Figs. 5 and 6. However, the improvement of visibility at the beginning of the lay-by and deterioration at its end can be observed in this case as well. The visibility drop starts near the walls and lay-by niche.

In horizontal tunnel the increase of the visibility at the beginning of the lay-by improves average visibility which is generally not sufficient. Therefore, the lay-by improves conditions for people. In sloped tunnel the visibility is generally very good, although the lay-by deteriorates conditions for people at some locations.

\subsection{Truck fire scenarios}

Behaviour of truck fire in sloped tunnel in L2 area is similar as in the case of passenger car fire (see Fig. 10). Lay-bys deteriorate visibility at head level even more significantly, which indicates that deterioration of conditions in the lay-by increases with increasing HRR. For $12 \mathrm{MW}$ fire, the lay-by deteriorates even the conditions in horizontal tunnel slightly (see Fig. 10) which is caused by thick smoke layer in that case.

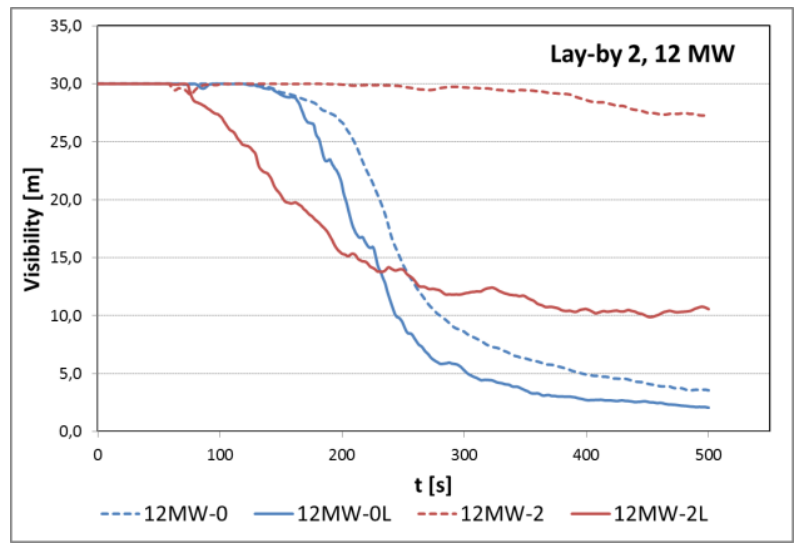

Figure 10: Average Visibility in the Second Lay-By for 12 MW Fires

Higher HRR of the truck fire allows investigating also the smoke behaviour in the first lay-by (L1 area) located upstream. The lay-by is afflicted by smoke due to the more significant backlayering which transfers the smoke upstream farther than in the cases of passenger car fires.

The decrease of visibility at head level starts in the fire vicinity due to cooled smoke entrained from the bottom part of the smoke layer downstream. The region with untenable conditions expands upstream slowly, i.e., for given time the visibility improves with the distance from the fire. The visibility pattern can be seen in Fig. 11.

In the case of horizontal tunnel, the smoke layer covers the entire ceiling of the lay-by and spreads out of the lay-by upstream. However, due to significant distance of the first lay-by, there is only a small decrease of average visibility at head level in it (see Fig. 12). Considerable decrease of visibility occurs locally in lay- by niche at the place for car parking while conditions in the central part of the lay-by are tenable.
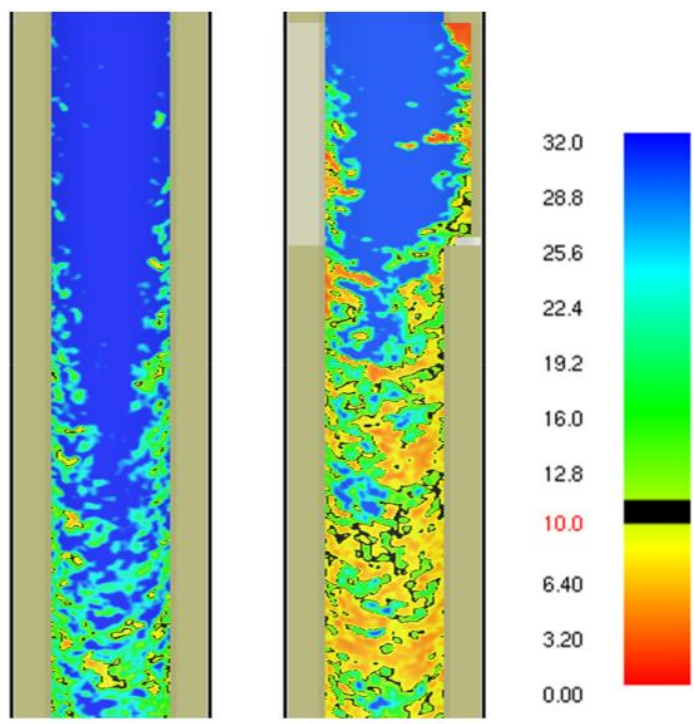

Figure 11: Vertical Slice of Visibility for Horizontal Tunnel Scenarios 12MW-0 and 12MW-0L: Areas L1 and $\mathrm{I} 1$ after $400 \mathrm{~s}$ to the Fire

The lay-by deteriorates conditions for people. Its geometry influences the spread of smoke in I1 area even more significantly causing enormous decrease of visibility occurring between 300 and $400 \mathrm{~s}$ to the fire (see Fig. 11). The vertical wall at the end of the lay-by disrupts the smoke layer intensifying its dissolution. Cooled smoke is entrained towards the fire and descends causing decrease of visibility in the fire vicinity.

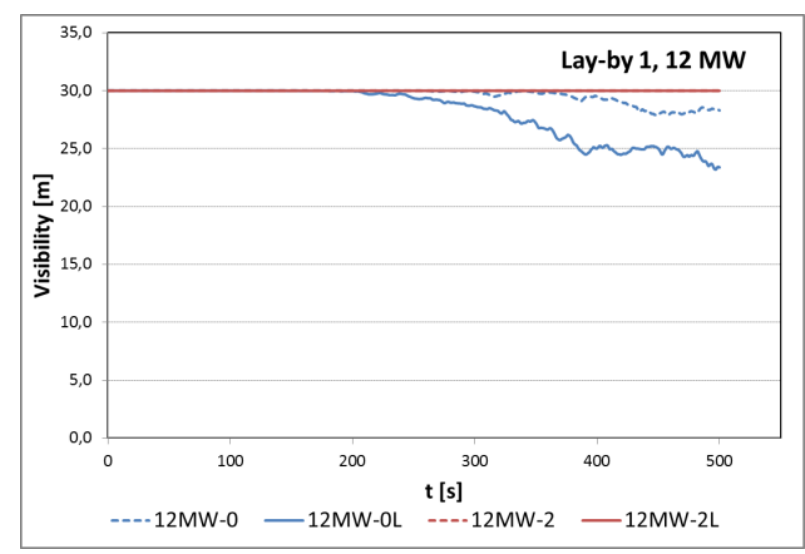

Figure 12: Average Visibility in the First Lay-By for 12 MW Fires

Note that the visibility decrease in the lay-by located upstream in horizontal tunnel may be more significant for shorter distance between the lay-by and the fire. The first lay-by in sloped tunnel is not afflicted by smoke due to the smaller length of smoke backlayering.

\subsection{Time-averaged visibilities}

The tendencies described above in detail can be presented in a schematic way using time-averaged 
values of visibility for the last $200 \mathrm{~s}$ of simulation. In Fig. 13 the time-averaged visibilities for all scenarios and all six areas of the tunnel are presented.

\begin{tabular}{|l|r|r|r|r|r|r|}
\hline & A1 & L1 & \multicolumn{1}{|l|}{ I } & \multicolumn{1}{c|}{ I2 } & \multicolumn{1}{c|}{ L2 } & \multicolumn{1}{c|}{ A2 } \\
\hline $3 \mathrm{MW}-0$ & 30.0 & 30.0 & 30.0 & 7.1 & 7.4 & 8.2 \\
\hline $3 \mathrm{MW}-0 \mathrm{~L}$ & 30.0 & 30.0 & 30.0 & 7.6 & 11.6 & 5.3 \\
\hline $3 \mathrm{MW}-2$ & 30.0 & 30.0 & 30.0 & 24.0 & 27.5 & 28.4 \\
\hline $3 \mathrm{MW}-2 \mathrm{~L}$ & 30.0 & 30.0 & 30.0 & 25.6 & 26.1 & 10.0 \\
\hline $5 \mathrm{MW}-0$ & 30.0 & 30.0 & 29.8 & 5.4 & 6.9 & 8.2 \\
\hline $5 \mathrm{MW}-0 \mathrm{~L}$ & 30.0 & 30.0 & 29.8 & 5.6 & 8.3 & 3.3 \\
\hline $5 \mathrm{MW}-2$ & 30.0 & 30.0 & 30.0 & 25.6 & 28.8 & 28.5 \\
\hline $5 \mathrm{MW}-2 \mathrm{~L}$ & 30.0 & 30.0 & 30.0 & 27.5 & 21.4 & 9.6 \\
\hline $12 \mathrm{MW}-0$ & 29.9 & 29.1 & 23.0 & 3.4 & 5.3 & 6.1 \\
\hline $12 \mathrm{MW}-0 \mathrm{~L}$ & 29.9 & 25.8 & 14.0 & 3.7 & 3.1 & 1.3 \\
\hline $12 \mathrm{MW}-2$ & 30.0 & 30.0 & 30.0 & 27.5 & 28.5 & 11.1 \\
\hline $12 \mathrm{MW}-2 \mathrm{~L}$ & 30.0 & 30.0 & 30.0 & 27.8 & 10.9 & 3.5 \\
\hline
\end{tabular}

Figure 13: Time-Averaged Visibility in Meters for the Last 200 s Period of the Simulations in Six Tested Areas for All Scenarios

The visibility is deteriorated in four types of cases:

- downstream of the fire (I2, L2 and A2 areas) in horizontal tunnels scenarios

- $\quad$ in the second lay-by and behind it (L2, A2) in lay bay sloped tunnel scenarios

- in A2 area for $12 \mathrm{MW}$ fire in sloped tunnel without lay-bys

- upstream of the fire behind the first lay-by (I1 area) for $12 \mathrm{MW}$ fire in horizontal tunnel.

Relative change of the visibility in six tested areas caused by lay-bys can be seen in Fig. 14. Blue colour marks areas in which lay-bys improve the visibility, while red colour indicates deterioration of visibility.

\begin{tabular}{|l|r|r|r|r|r|r|}
\hline & A1 & \multicolumn{1}{|c|}{ L1 } & \multicolumn{1}{c|}{ I1 } & \multicolumn{1}{c|}{ I2 } & \multicolumn{1}{c|}{ L2 } & \multicolumn{1}{c|}{ A2 } \\
\hline $3 \mathrm{MW}-0$ & 0.00 & 0.00 & 0.00 & 0.08 & 0.57 & -0.35 \\
\hline $3 \mathrm{MW}-2$ & 0.00 & 0.00 & 0.00 & 0.07 & -0.05 & -0.65 \\
\hline $5 \mathrm{MW}-0$ & 0.00 & 0.00 & 0.00 & 0.04 & 0.22 & -0.60 \\
\hline $5 \mathrm{MW}-2$ & 0.00 & 0.00 & 0.00 & 0.07 & -0.26 & -0.66 \\
\hline $12 \mathrm{MW}-0$ & 0.00 & -0.11 & -0.39 & 0.08 & -0.42 & -0.79 \\
\hline $12 \mathrm{MW}-2$ & 0.00 & 0.00 & 0.00 & 0.01 & -0.62 & -0.68 \\
\hline
\end{tabular}

Figure 14: Relative Change of Time-Averaged Visibility in Six Tested Areas Caused by Lay-Bys Included in the Tunnel

A significant improvement due to lay-by installation occurs in two cases in which conditions are untenable, while a slight improvement occurs in the I 2 area in all tested cases.

Deterioration of visibility occurs in the A2 area in all scenarios. For more intensive fires visibility deteriorates also in the second lay-by area (L2) and also behind the first lay-by for $12 \mathrm{MW}$ fire in horizontal tunnel scenario.

\section{CONCLUSION}

Series of 12 parallel simulations of tunnel fire have been performed by FDS to investigate the influence of emergency lay-bys on smoke stratification in a $900 \mathrm{~m}$ long road tunnel.

Specific geometry of the lay-by located downstream improves visibility at head level in the front area of the lay-by and deteriorates it in the rear area. In horizontal tunnel the first mentioned effect prevails and the lay-by improves conditions for people, which would otherwise be untenable after 5 minutes to the fire. In the case of sloped tunnel the conditions are tenable within almost whole tunnel tube and the lay-by causes a local untenability of conditions at the end of the lay-by and behind it which becomes significant for more intensive fires.

Decrease of visibility in the lay-by located upstream occurs only if the length of backlayering is sufficient to achieve its location, i.e., for more intensive fires. In such case only a slight drop of visibility can be observed. However, significant deterioration of visibility occurs in the area between this lay-by and the fire.

In other sections of the tunnel the effect of the lay-by on smoke stratification is very small.

\section{ACKNOWLEDGMENTS}

The authors would like to thank Peter Schmidt (National Motorway Company, Slovakia) for information about technical specifications of road tunnels. This paper was partially supported by the Slovak Science Foundation (project VEGA 2/0165/17) and the Slovak Research and Development Agency (project No. APVV-15-0340).

\section{REFERENCES}

Boehm M., Fournier L., Truchot B, 2008. Smoke stratification stability: presentation of experiments. Proceedings of $4^{\text {th }}$ International Conference on Tunnel Safety and Ventilation, pp 176-182. April 21-23, Graz (Austria).

Danisovic P., Sramek J., Hodon M., Hudik M., 2017. Testing measurements of airflow velocity in road tunnels. MATEC Web of Conferences, 117, 00035 .

Klote J., Milke, J., 1992. Design of smoke management systems. American Society of Heating, Refrigerating and Air Conditioning Engineers. Atlanta, Georgia, USA.

McGrattan K., Hostikka S., McDermott R., Floyd J., Weinschenk C. and Overholt K., 2017. Fire Dynamics Simulator, Technical Reference Guide (sixth edition). National Institute of Standards and Technology. Gaithersburg, Maryland, USA, and VTT Technical Research Centre of Finland, Espoo, Finland.

Rattei G., 2010. Safety installations in road tunnels are they used in incident cases? Proceedings of $5^{\text {th }}$ International Conference on Tunnel Safety and Ventilation, pp 235-241. May 3-4, Graz (Austria). 
SIVVP. Slovak Infrastructure for High Performance Computing. Available from: http://www.sivvp.sk/

TP 12/2011, 2011. Road tunnels ventilation (in Slovak). Ministry of Transport and Construction of the Slovak Republic. Bratislava, Slovakia.

Weisenpacher P., Glasa J., Sipkova V., 2016. Performance of FDS versions 5 and 6 in passenger car fire computer simulation. Proceedings of European Modeling and Simulation Symposium, 2016, pp. 156-161. September 26-28, Larnaca (Cyprus).

Weisenpacher P., Glasa J., Valasek L., 2017. Computer simulation of smoke stratification during fire in bidirectional road tunnel by FDS 6. Proceedings of the MCS-10: Tenth Mediterranean Combustion Symposium. September 17-21, Naples (Italy).

Weisenpacher P., Glasa J., Valasek L., 2018. Influence of slope and external temperature on smoke stratification in case of fire in bi-directional road tunnel. ITM Web of Conferences, 16, 02002. 